\title{
Increased DCLK1 correlates with the malignant status and poor outcome in malignant tumors: a meta-analysis
}

\author{
Wenhua Shi ${ }^{1}$, Fangwei $\mathrm{Li}^{1}$, Shaojun $\mathrm{Li}^{1}$, Jian $\mathrm{Wang}^{1}$, Qingting Wang ${ }^{1}$, Xin $\mathrm{Yan}^{1}$, \\ Qianqian Zhang ${ }^{1}$, Limin Chai ${ }^{1}$ and Manxiang Li ${ }^{1}$ \\ ${ }^{1}$ Department of Respiratory and Critical Care Medicine, The First Affiliated Hospital of Xi'an Jiaotong University, Xi'an, \\ Shaanxi 710061, China
}

Correspondence to: Manxiang Li, email: manxiangli@hotmail.com

Keywords: DCLK1, tumors, biomarker, diagnosis, meta-analysis

Received: June 19, 2017 Accepted: July 30, $2017 \quad$ Published: August 10, 2017

Copyright: Shi et al. This is an open-access article distributed under the terms of the Creative Commons Attribution License 3.0 (CC BY 3.0), which permits unrestricted use, distribution, and reproduction in any medium, provided the original author and source are credited.

\section{ABSTRACT}

Doublecortin-like kinase 1 (DCLK1) has been found to be involved in malignant biological behavior of cancers and poor prognosis of cancer patients. The aim of this meta-analysis was to systematically clarify the relationships between expression level of DCLK1 and clinicopathological characteristics in tumors and assess its clinical value in cancer diagnosis and prognosis. 18 eligible studies with a total of 2660 patients were identified by searching the electronic bibliographic databases. Pooled results showed that DCLK1 was highly expressed in tissues from cancer patients compared to normal tissues $(O R, 10.00)$, and overexpression of DCLK1 was significantly correlated with advanced clinical stage (OR, 2.48), positive lymph node metastasis (OR, 2.18), poorly differentiated cancers $(O R, 1.83)$ and poor overall survival $(H R, 2.15)$. The overall combined sensitivity and specificity for DCLK1 in distinguishing malignant

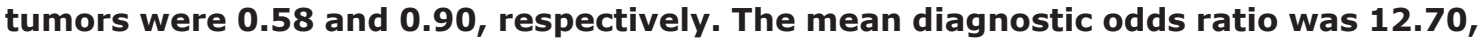
and the corresponding area under the summary receiver operating characteristic curve was 0.78 . In summary, our study indicated that DCLK1 could be a risk factor for development of malignant tumors and may serve as a promising diagnostic and prognostic biomarker for malignant tumors.

\section{INTRODUCTION}

Cancer is one of the leading causes of mortality and is a major public health problem worldwide. It has been reported that $1,688,780$ new cancer cases and 600,920 cancer deaths are projected to occur in the United States in 2017 [1]. Despite medical and scientific efforts over the past decades, patients with malignant tumors often face poor clinical outcomes [2]. It has been demonstrated that the early diagnosis and reliable prediction for recurrences are critical for the prognosis of cancer patients [3]. Of note, biomarkers are already important adjuvant tools for refining and optimizing diagnosis, treatment, and prognosis [4]. However, currently established biomarkers, due to limited validation and questionable prognostic values, could not qualify as reliable biomarkers for early diagnosis and prognosis assessment in clinical practice [5]. Therefore, it will be of enormous importance to identify new markers to help diagnose tumors, predict clinical outcomes and serve as therapeutic targets.

Doublecortin-like kinase 1 (DCLK1) is a microtubule-associated protein that catalyzes the polymerization of tubulin dimmers and the formation of aster-like microtubule structures [6]. DCLK1 has been identified to be involved in tumorigenesis of various types of cancer, such as renal cell carcinoma (RCC) [7], pancreatic ductal adenocarcinoma (PDAC) [8], colorectal cancer (CRC) [9] and breast carcinoma (BCA) [10]. In addition, it has been demonstrated that DCLK1 is associated with malignant biological behavior and poor prognosis of cancer $[11,12]$. Knockdown of DCLK1 has been shown to significantly reduce invasion, migration and focal adhesion of RCC cells, indicating that DCLK1 may be a potential therapeutic target for RCC [7]. Although quite a number of studies have suggested that DCLK1 could be a risk factor and prognostic biomarker for 
malignant tumors, the relationships between expression level of DCLK1 and clinicopathological characteristics in tumors, especially for the clinical stage, lymph node metastasis and the degree of tumor differentiation, are still largely unknown and deserve further research. Therefore, we conducted the comprehensive meta-analysis on all eligible studies to clarify these and assess the clinical value of DCLK1 in cancer diagnosis and prognosis, thereby providing more evidence for clinical practice and accelerating further investigations.

\section{RESULTS}

\section{Searching process of literature}

The complete literature search yielded 406 articles: 116 from PubMed, 105 from Medline, 4 from Embase, 112 from Chinese National Knowledge Infrastructure (CNKI) and 69 from Wanfang databases. And 284 articles were screened based on titles and abstracts after removing 122 duplicates. Among these articles, 266 articles were excluded for the following reasons: obviously not relevant to the topic $(n=218)$, non-human studies $(n=18)$, not clearly report data of DCLK1 $(n=11)$, reviews or expert opinions $(n=10)$, contain overlapping data $(n=7)$, serum samples $(n=2)$. Finally, 18 articles were included in this meta-analysis. Figure 1 is a flow diagram outlining the study-selection process.

\section{Study characteristics}

As shown in Table 1, 18 studies [8-25] investigated the association between DCLK1 expression and clinicopathological characteristics in patients with cancer from 2012 to 2017, containing a total of 2660 patients with the sizes of studies distributing from 23 [18] to 1132 [10] patients. All studies were retrospective, and most of studies adopted immunohistochemistry (IHC) to detect the expression of DCLK1 in cancer tissues samples that composed of malignant cell and a supporting stroma, while one adopted reverse transcription-polymerase chain reaction (RT-PCR). The source of the malignant tumor included PDAC [8], CRC [9, 16, 17, 19, 22, 23], BCA $[10,15]$, head and neck squamous cell carcinoma (HNSCC) [11], non-small cell lung cancer (NSCLC) [12], oral squamous-cell carcinoma (OSCC) [13], gastric cancer (GC) [14, 20], hepatocellular carcinoma (HCC) [18], salivary gland carcinoma (SGC) [21], malignant pleural mesothelioma (MPM) [24] and bladder cancer (BC) [25]. In these studies, most of investigations were in Asia, including China and Japan. Four studies were in America $[8,18,23,24]$, and two studies were in Austria [11, 21].

\section{Cancer group vs. control group}

Eleven studies investigated the expression patterns of DCLK1 in various cancer and normal tissues [9, 13-20,
24, 25], which included 742 cancer cases and 508 normal controls (Table 2). The overall odds ratio (OR) was 10.00 $(95 \% \mathrm{CI}=7.20-13.89)(\mathrm{Z}=13.75, p<0.001)$ (Figure $2 \mathrm{~A})$. Subgroup analysis was stratified according to geographic region. The summary OR in Asian region was $9.25(95 \%$ $\mathrm{CI}=6.61-2.94, P<0.001)$ and $48.61(95 \% \mathrm{CI}=5.89$ $401.25, P<0.001$ ) in non-Asia region (Table 3). Significant association existed between DCLK1 level and cancer tissues, indicating that expression of DCLK1 was dramatically higher in cancer tissues than that in normal tissues.

\section{Clinical stages of cancers: advanced stage vs. early stage}

Eleven studies [8, 9, 14, 15, 17, 18, 21-25] investigated the expressions of DCLK1 in different clinical stages of cancers. Patients with cancer were divided into early stage (I-II stage) and advanced stage (III-IV stage) based on the tumor-node-metastasis (TNM) classification: 266 cancer cases of early stage and 380 cases of advanced stage (Table 2). The overall OR was 2.48 (95\% CI = $1.82-3.38)(Z=5.78, p<0.001)$ via a fixed model analysis (Figure 2B). Subgroup analysis stratified by study region showed that the summary OR was $1.21(95 \% \mathrm{CI}=$ $0.67-2.19, P<0.001)$ in non-Asia countries while was $3.29(95 \% 95 \% \mathrm{CI}=2.28-4.76, P<0.001)$ in Asian countries with significant association (Table 3), suggesting that expression level of DCLK1 was dramatically higher in advanced stage group than that in early stage group.

\section{Lymph node metastasis of cancers: positive group vs. negative group}

Fourteen studies [9-12, 14-22, 25] investigated the expressions of DCLK1 in different status of lymphatic metastasis, including 1172 cases of positive lymphatic metastasis and 1199 cases of negative lymphatic metastasis (Table 2). The overall OR was $2.18(95 \% \mathrm{CI}=$ $1.53-3.11)(Z=4.31, p<0.001)$, indicating that expression level of DCLK1 was markedly higher in positive group than that in negative group. We used a random-effect model justified by the high heterogeneity $\left(\mathrm{I}^{2}=55.60 \%\right.$, $p=0.006$ ) (Figure 2C). Subgroup analysis stratified by study region showed that the summary OR of Asian studies was $2.76(95 \% \mathrm{CI}=2.29-3.33, p<0.001)$ with significant association. However, the statistic significance in non-Asia region disappeared $(\mathrm{OR}=0.9,95 \% \mathrm{CI}=0.48$ $1.71, p>0.05$ ) (Table 3).

\section{Degree of tumor differentiation: poor group vs. well and moderate group}

As shown in Table 2, ten studies [9, 10, 14-17, $19,22,23,25]$ investigated the expressions of DCLK1 in different degree of tumor differentiation, including 1411 cases of well and moderate differentiation and 389 cases of poor differentiation. The overall OR was 1.83 
Table 1: Main characteristics of the 18 studies included in the meta-analysis

\begin{tabular}{|c|c|c|c|c|c|c|c|c|c|c|c|c|c|c|c|c|}
\hline \multirow{2}{*}{ Source } & \multirow[t]{2}{*}{ Author } & \multirow[t]{2}{*}{ Year } & \multirow[t]{2}{*}{ Country } & \multirow{2}{*}{$\begin{array}{l}\text { Enrolled } \\
\text { period }\end{array}$} & \multirow{2}{*}{$\begin{array}{l}\text { Research } \\
\text { design }\end{array}$} & \multirow{2}{*}{$\begin{array}{l}\text { Resources } \\
\text { of samples }\end{array}$} & \multirow{2}{*}{$\begin{array}{l}\text { Test } \\
\text { method }\end{array}$} & \multirow{2}{*}{$\begin{array}{l}\text { Cancer } \\
\text { /control }\end{array}$} & \multicolumn{2}{|l|}{ Cancer } & \multicolumn{2}{|c|}{$\begin{array}{l}\text { Tumor stage } \\
\text { (N) }\end{array}$} & \multicolumn{2}{|c|}{$\begin{array}{l}\text { Tumor } \\
\text { differentiation(N) }\end{array}$} & \multicolumn{2}{|c|}{$\begin{array}{l}\text { Lymphatic } \\
\text { Metastasis } \\
\text { (N) }\end{array}$} \\
\hline & & & & & & & & & Age & $\mathbf{M} / \mathbf{F}(\mathbf{n})$ & I-II & $\begin{array}{l}\text { III- } \\
\text { IV }\end{array}$ & $\begin{array}{l}\text { Well to } \\
\text { moderate }\end{array}$ & Poor & Yes & No \\
\hline \multirow[t]{6}{*}{ CRC } & $\begin{array}{l}\text { Tianbo Gao } \\
{[9]}\end{array}$ & 2016 & China & 2007 to 2011 & Retrospective & Tumor tissue & IHC & $71 / 16$ & 60 & $44 / 27$ & 28 & 43 & 61 & 10 & 41 & 30 \\
\hline & $\begin{array}{l}\text { Huan Wang } \\
{[16]}\end{array}$ & 2015 & China & 2007to 2012 & Retrospective & Tumor tissue & $\mathrm{IHC}$ & $150 / 20$ & 58.4 & $91 / 59$ & - & - & 95 & 36 & 66 & 84 \\
\hline & Anjun Le [19] & 2015 & China & 2007 to 2008 & Retrospective & Tumor tissue & $\mathrm{IHC}$ & $70 / 70$ & $52.6 \pm 10.5$ & $42 / 28$ & - & - & 21 & 49 & 36 & 34 \\
\hline & $\begin{array}{l}\text { Shuxiang An } \\
{[17]}\end{array}$ & 2015 & China & 2009 to 2013 & Retrospective & Tumor tissue & $\mathrm{IHC}$ & $60 / 20$ & - & $38 / 22$ & 34 & 26 & 48 & 12 & 25 & 35 \\
\hline & $\begin{array}{l}\text { Malaney } R \\
\text { O'Connell } \\
{[22]}\end{array}$ & 2015 & Japan & 2005 to 2011 & Retrospective & Tumor tissue & $\begin{array}{l}\text { RT- } \\
\text { PCR }\end{array}$ & $92 / 0$ & 68 & $57 / 35$ & 49 & 43 & 82 & 10 & 41 & 51 \\
\hline & $\begin{array}{l}\text { Giuseppe } \\
\text { Gagliardi [23] }\end{array}$ & 2012 & USA & 2000 to 2010 & Retrospective & Tumor tissue & $\mathrm{IHC}$ & $40 / 0$ & 66 & $23 / 17$ & 14 & 26 & 26 & 14 & - & - \\
\hline \multirow[t]{2}{*}{$\mathrm{GC}$} & Lin Chen [14] & 2015 & China & $\begin{array}{l}2013.3 \text { to } \\
2013.10\end{array}$ & Retrospective & Tumor tissue & $\mathrm{IHC}$ & $49 / 49$ & $28 \sim 70$ & $27 / 22$ & 19 & 30 & 22 & 27 & 36 & 13 \\
\hline & $\begin{array}{l}\text { Qingbin Meng } \\
{[20]}\end{array}$ & 2013 & China & 2002 to 2006 & Retrospective & Tumor tissue & $\mathrm{IHC}$ & $122 / 122$ & 62 & $86 / 36$ & - & - & - & - & 85 & 37 \\
\hline \multirow[t]{2}{*}{$\mathrm{BCA}$} & $\begin{array}{l}\text { Jingjing Gan } \\
{[15]}\end{array}$ & 2016 & China & 2005 to 2007 & Retrospective & Tumor tissue & IHC & $129 / 129$ & 53 & $0 / 129$ & 56 & 73 & 86 & 43 & 94 & 35 \\
\hline & $\begin{array}{l}\text { Yuhong Liu } \\
{[10]}\end{array}$ & 2015 & China & 2002 to 2009 & Retrospective & Tumor tissue & $\mathrm{IHC}$ & $1132 / 0$ & $54.6 \pm 12.7$ & $0 / 1132$ & - & - & 630 & 502 & 542 & 557 \\
\hline NSCLC & $\begin{array}{l}\text { Hiroyuki Tao } \\
{[12]}\end{array}$ & 2017 & Japan & 2005 to 2009 & Retrospective & Tumor tissue & IHC & $232 / 0$ & 61 & $128 / 104$ & 232 & - & - & - & 39 & 193 \\
\hline $\mathrm{HCC}$ & $\begin{array}{l}\text { Sripathi M. } \\
\text { Sureban [18] }\end{array}$ & 2015 & USA & 2000 to 2010 & Retrospective & Tumor tissue & $\mathrm{IHC}$ & $23 / 23$ & $62 \pm 13.8$ & $10 / 13$ & 4 & 18 & - & - & 11 & 12 \\
\hline SGC & $\begin{array}{l}\text { Lorenz } \\
\text { Kadletz [21] }\end{array}$ & 2017 & Austria & 1970 to 2013 & Retrospective & Tumor tissue & $\mathrm{IHC}$ & $80 / 0$ & 58 & $43 / 37$ & 41 & 39 & - & - & 58 & 22 \\
\hline HNSCC & $\begin{array}{l}\text { Lorenz } \\
\text { Kadletz [11] }\end{array}$ & 2017 & Austria & 2002 to 2012 & Retrospective & Tumor tissue & $\mathrm{IHC}$ & $127 / 0$ & 57.7 & - & 20 & 107 & - & - & 99 & 28 \\
\hline OCCC & Xin Wu [13] & 2017 & China & 2013 to 2014 & Retrospective & Tumor tissue & $\mathrm{IHC}$ & $30 / 30$ & - & - & - & - & - & - & - & - \\
\hline PDAC & $\begin{array}{l}\text { Dongfeng Qu } \\
{[8]}\end{array}$ & 2015 & USA & - & Retrospective & Tumor tissue & $\mathrm{IHC}$ & $12 / 62$ & 64 & $35 / 27$ & 31 & 31 & - & - & - & - \\
\hline MPM & Hui Wang [24] & 2017 & USA & 1997 to 2008 & Retrospective & Tumor tissue & $\mathrm{IHC}$ & $73 / 8$ & 68.13 & - & 15 & 17 & - & - & - & - \\
\hline $\mathrm{BC}$ & $\begin{array}{l}\text { Shiqing Zhang } \\
{[25]}\end{array}$ & 2017 & China & 2005 to 2015 & Retrospective & Tumor tissue & IHC & $118 / 40$ & - & $79 / 39$ & 49 & 69 & 80 & 38 & 16 & 102 \\
\hline
\end{tabular}

CRC, colorectal cancer; GC, gastric cancer; BCA, breast carcinoma; NSCLC, non-small cell lung cancer; HCC, hepatocellular carcinoma; SGC, salivary gland carcinoma; HNSCC, head and neck squamous cell carcinoma; OSCC, oral squamous-cell carcinoma; PDAC, pancreatic ductal adenocarcinoma; MPM, malignant pleural mesothelioma; BC, bladder cancer; IHC, immunohistochemistry, RT-PCR, real time polymerase chain reaction.

$(95 \% \mathrm{CI}=1.45-2.31)(\mathrm{Z}=5.06, p<0.001)$, indicating that expression level of DCLK1 was relatively higher in the poor group than that in the well and moderate group (Figure 2D). Subgroup analysis stratified by study region showed that the summary OR in Asian region was 1.87 $(95 \% \mathrm{CI}=1.47-2.37, p<0.001)$ and $0.9(95 \% \mathrm{CI}=0.22-$ $3.75, P>0.05$ ) in non-Asia region (Table 3). Significant association only existed in Asia.

\section{Correlation between DCLK1 expression and overall survival (OS)}

In order to investigate the association between DCLK1 expression and clinical outcome in malignant tumors, patients were divided into DCLK1-high and DCLK1-low groups. Based on the results of univariate analysis in the original studies, a total of 7 pairs of hazard ratio (HR) for OS were available in the 18 studies $[11,12,15,20,22,23$, 25] (Table 2). The combined HR was $2.15(95 \%$ $\mathrm{CI}=1.64-2.65)(\mathrm{Z}=8.33, p<0.001)$ (Figure 3$)$. Subgroup analysis stratified by study region showed that the summary HR in Asian region was 2.17 (95\% CI = $1.60-2.74, p<0.001)$ and $2.07(95 \% \mathrm{CI}=0.98-3.15$, $p<0.001)$ in non-Asia region. Significant association existed between DCLK1 level and OS (Table 3), indicating that DCLK1 may act as a potential marker for predicting survival outcomes in patients with cancer. 
Table 2: DCLK1 expression in control and cancer patients

\begin{tabular}{|c|c|c|c|c|c|c|c|c|c|c|c|c|c|}
\hline \multirow{3}{*}{ Author } & \multirow{3}{*}{$\begin{array}{c}\text { Control } \\
(n)\end{array}$} & \multirow{3}{*}{$\begin{array}{l}\text { Cancer } \\
((n)\end{array}$} & \multicolumn{6}{|c|}{ Expression of DCLK1 (positive/all) ( $n$ ) } & \multicolumn{4}{|c|}{ Diagnostic test } & \multirow{3}{*}{$\begin{array}{c}\text { OS } \\
\text { HR }(95 \% \mathrm{CI})(\mathrm{U})\end{array}$} \\
\hline & & & \multicolumn{2}{|c|}{ Tumor stage (n) } & \multicolumn{2}{|c|}{$\begin{array}{c}\text { Tumor } \\
\text { differentiation }(n)\end{array}$} & \multicolumn{2}{|c|}{$\begin{array}{c}\text { Lymphatic } \\
\text { metastasis(n) }\end{array}$} & \multirow{2}{*}{ TP } & \multirow{2}{*}{$\mathbf{F P}$} & \multirow{2}{*}{$\mathbf{F N}$} & \multirow{2}{*}{ TN } & \\
\hline & & & I-II & III-IV & $\begin{array}{c}\text { Well to } \\
\text { moderate }\end{array}$ & Poor & Yes & No & & & & & \\
\hline Tianbo Gao [9] & $5 / 16$ & $43 / 71$ & $10 / 28$ & $33 / 43$ & $36 / 61$ & $7 / 10$ & $31 / 41$ & $12 / 30$ & 43 & 5 & 28 & 11 & - \\
\hline Huan Wang [16] & $0 / 20$ & $95 / 150$ & - & - & $38 / 95$ & $16 / 36$ & $26 / 66$ & $34 / 84$ & 95 & 0 & 55 & 20 & - \\
\hline Anjun Le [19] & $3 / 70$ & $29 / 70$ & - & - & $4 / 21$ & $25 / 49$ & $20 / 36$ & $9 / 34$ & 29 & 3 & 41 & 67 & - \\
\hline Shuxiang An [17] & $4 / 20$ & $39 / 60$ & $18 / 34$ & $21 / 26$ & $23 / 48$ & $6 / 12$ & $20 / 25$ & $19 / 35$ & 39 & 4 & 21 & 16 & - \\
\hline Malaney R O'Connell [22] & - & $46 / 92$ & $20 / 49$ & $26 / 43$ & $40 / 82$ & $6 / 10$ & $25 / 41$ & $21 / 51$ & - & - & - & - & $3.55(1.41-8.99)$ \\
\hline Giuseppe Gagliardi [23] & - & $27 / 40$ & $10 / 14$ & $17 / 26$ & $8 / 26$ & $4 / 14$ & - & - & - & - & - & - & $4.16(1.28-13.57)$ \\
\hline Lin Chen [14] & $18 / 49$ & $36 / 49$ & $7 / 19$ & $22 / 30$ & $6 / 22$ & $18 / 27$ & $25 / 36$ & $4 / 13$ & 36 & 18 & 13 & 31 & - \\
\hline Qingbin Meng [20] & $4 / 122$ & $51 / 122$ & - & - & - & - & $41 / 85$ & $10 / 37$ & 51 & 4 & 71 & 118 & $2.27(1.36-3.80)$ \\
\hline Jingjing Gan [15] & $15 / 129$ & $58 / 129$ & $18 / 56$ & $40 / 73$ & $28 / 86$ & $30 / 43$ & $48 / 94$ & $10 / 35$ & 58 & 15 & 71 & 114 & $2.12(1.24-3.71)$ \\
\hline Yuhong Liu [10] & - & $418 / 1132$ & - & - & $277 / 630$ & $141 / 502$ & $178 / 542$ & $222 / 557$ & - & - & - & - & - \\
\hline Hiroyuki Tao [12] & - & $33 / 232$ & $33 / 232$ & - & - & - & $5 / 39$ & $28 / 193$ & - & - & - & - & $1.80(1.13-2.85)$ \\
\hline Sripathi M. Sureban [18] & $0 / 20$ & $19 / 23$ & $3 / 4$ & $16 / 18$ & - & - & $9 / 11$ & $10 / 12$ & 15 & 1 & 8 & 19 & - \\
\hline Lorenz Kadletz [21] & - & $53 / 80$ & $9 / 41$ & $11 / 39$ & - & - & $15 / 58$ & $6 / 22$ & - & - & - & - & - \\
\hline Lorenz Kadletz [11] & - & $66 / 127$ & - & - & - & - & $50 / 99$ & $15 / 28$ & - & - & - & - & $2.00(1.20-3.40)$ \\
\hline Xin Wu [13] & $4 / 30$ & $23 / 30$ & - & - & - & - & - & - & 23 & 4 & 7 & 26 & - \\
\hline Dongfeng Qu [8] & - & $23 / 44$ & $10 / 22$ & $13 / 22$ & - & - & - & - & - & - & - & - & - \\
\hline Hui Wang [24] & $0 / 8$ & $37 / 73$ & $9 / 15$ & $9 / 17$ & - & - & - & - & 38 & 35 & 0 & 8 & - \\
\hline Shiqing Zhang [25] & $5 / 40$ & $65 / 118$ & $18 / 49$ & $47 / 69$ & $40 / 80$ & $25 / 38$ & $15 / 16$ & $50 / 102$ & 66 & 52 & 5 & 35 & $3.35(2.01-5.6)$ \\
\hline
\end{tabular}

n, cases; TP, true positive; FP, false positive; FN, false negative; TN, true negative; OS, overall survival; HR, hazard ratio; U, univariate analysis

\section{Accuracy of DCLK1 for diagnosing cancers}

A total of 11 studies reported sensitivity and specificity for distinguishing cancers and normal tissues $[9,13-20,24,25]$. The computation of Spearman correlation coefficient between the logit of sensitivity and logit of 1-specificity showed no evidence of a threshold effect (Spearman correlation coefficient $=-0.58 ; \mathrm{p}=$ $0.34)$. The overall combined sensitivity, specificity, positive likelihood ratio (PLR), negative likelihood ratio (NLR), diagnostic score and relevant $95 \%$ CI were as follows: 0.58 (95\% CI $=0.51-0.66)$ (Figure 4A), 0.90 $(95 \% \mathrm{CI}=0.82-0.95)$ (Figure 4B), $5.9(95 \% \mathrm{CI}=3.3-$ $10.5)$ (Figure 4C), $0.46(95 \% \mathrm{CI}=0.39-0.55)$ (Figure 4D) and $2.54(95 \% \mathrm{CI}=1.90-3.18)$ (Figure 4E), respectively. Significant heterogeneity was observed for sensitivity $\left(\mathrm{I}^{2}\right.$ $=78.68 \%, p<0.001)$, specificity $\left(\mathrm{I}^{2}=84.66 \%, p<\right.$ $0.001), \operatorname{PLR}\left(\mathrm{I}^{2}=64.50 \%, p<0.001\right), \mathrm{NLR}\left(\mathrm{I}^{2}=72.03 \%\right.$, $p<0.001)$ and diagnostic score $\left(\mathrm{I}^{2}=51.14 \%, p<0.001\right)$.
The mean diagnostic odds ratio (DOR) was 12.70 (95\% $\mathrm{CI}=6.68-24.15)$ (Figure 4F), indicating that DCLK1 level in cancer tissues could be helpful in the diagnosis of malignant tumors. The summary receiver operating characteristic (SROC) curve analysis was used to analyze the effectiveness of DCLK1 for diagnostic purposes, the corresponding area under the SROC curve (AUC) was 0.78 (Figure 4G), revealing moderate diagnostic accuracy overall.

\section{Meta-regression and subgroup analysis}

To explore the sources of high heterogeneity in sensitivity and specificity, we performed univariate metaregression and subgroup analysis according to sample size, study design, detection method and geographic region. As shown in Figure 5, sample size may be a significant impact factor for the high heterogeneity in this meta-analysis. In studies with more than 50 subjects, the 
pooled sensitivity, specificity, PLR, NLR, DOR, AUC of DCLK1 were $0.62(95 \% \mathrm{CI}=0.44-0.77), 0.85(95 \% \mathrm{CI}$ $=0.67-0.94), 4.1(95 \% \mathrm{CI}=2.1-7.9), 0.45(95 \% \mathrm{CI}=$ 0.32-0.62), 9 (95\% CI $=5-116)$ and 0.79, respectively. And those for studies with fewer subjects were 0.76 (95\% CI $=0.67-0.84), 0.78$ (95\% CI $=0.68-0.86), 4.78$ (95\% CI $=1.21-18.88), 0.30$ (95\% CI $=0.20-0.47), 17$ $(95 \% \mathrm{CI}=3-93)$ and 0.81 , respectively, which indicated a comparable diagnostic accuracy between the large- and small-sample studies. Similar results were found in the subgroup analyses according to study design, detection method and geographic region (Table 4).

\section{Quality assessment of studies}

Two reviewers evaluated the quality of each study independently, most of 18 studies had more than 5 stars of scores based on Newcastle-Ottawa Scale (NOS) (Supplementary Table 1). Figure 6A and 6B showed the results of study methodological quality evaluation according to Quality Assessment of Diagnostic Accuracy Studies (QUADAS-2) items, suggesting that the overall quality of included studies was moderate to high.

\section{Publication bias and sensitivity analysis}

The funnel plot was used to evaluate publication bias, and the shape of the funnel appeared to be approximately symmetrical. Furthermore, no significant publication bias was detected by Egger's test and Deeks' funnel plot (Supplementary Figures 1 and 2). The stability of the results was detected by sensitivity analysis, we found that exclusion of individual studies has no effect on the overall results (Supplementary Figure 3).

\section{DISCUSSION}

In this meta-analysis including 18 retrospective studies with a total of 2660 patients, we clarified the association between expression of DCLK1 and the clinicopathological characteristics of malignant tumors. Our results indicated that the expression of DCLK1 in cancer tissues was significantly higher than that in normal or adjacent non-tumor tissues. After implementing a series of subgroup analysis, we noticed that high expression of DCLK1 was significantly correlated with poorly

116 records from PubMed, 4 records from Embase,

105 records from Medline, 112 records from CNKI,

69 records from Wanfang databases

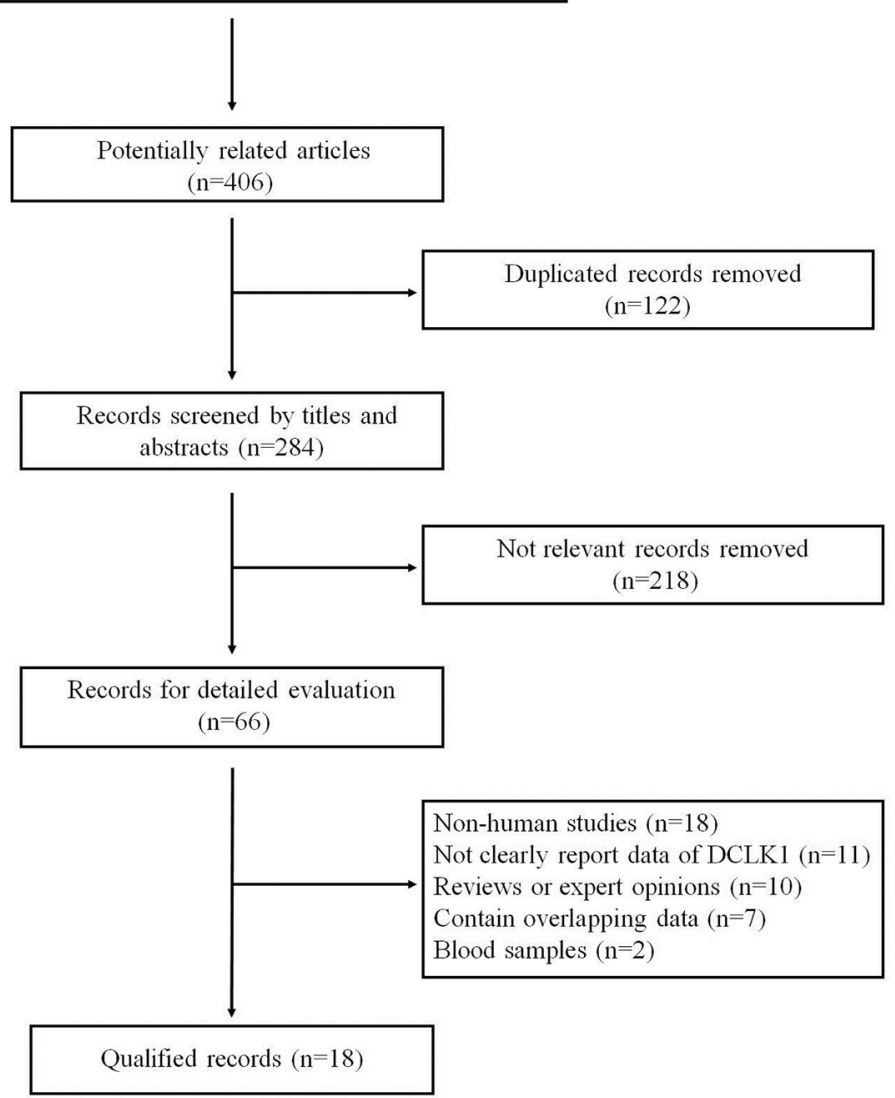

Figure 1: The flow diagram of study selection for meta-analysis. 
Table 3: Subgroup analysis of study region

\begin{tabular}{|c|c|c|c|c|c|c|c|c|c|}
\hline Subgroup & Region & $\begin{array}{c}\text { Study }(n) \\
\text { number }\end{array}$ & $\begin{array}{l}\text { Patients } \\
\text { (n) }\end{array}$ & $\begin{array}{c}\text { Controls } \\
(n)\end{array}$ & OR/HR & (95\% Conf.Interval) & $Z$ & $P$ & $\mathbf{I}^{2}$ \\
\hline \multirow{3}{*}{ Cancer vs. control } & overall & 11 & 742 & 508 & 10.00 & $(7.20-13.89)$ & 13.75 & $<0.001$ & $44.00 \%$ \\
\hline & Asia & 9 & 649 & 460 & 9.25 & $(6.61-12.94)$ & 12.99 & $<0.001$ & $39.90 \%$ \\
\hline & non-Asia & 2 & 96 & 48 & 48.61 & $(5.89-401.25)$ & 3.61 & $<0.001$ & $13.50 \%$ \\
\hline \multirow{3}{*}{ TNM stage } & overall & 11 & 380 & 266 & 2.48 & $(1.82-3.38)$ & 5.78 & $<0.001$ & $18.80 \%$ \\
\hline & Asia & 6 & 284 & 188 & 3.29 & $(2.28-4.76)$ & 6.34 & $<0.001$ & $0.00 \%$ \\
\hline & non-Asia & 5 & 96 & 78 & 1.21 & $(0.67-2.19)$ & 3.02 & $<0.001$ & $0.00 \%$ \\
\hline \multirow{3}{*}{ Lymph node metastasis } & overall & 14 & 1172 & 1199 & 2.18 & $(1.53-3.11)$ & 4.31 & $<0.001$ & $55.60 \%$ \\
\hline & Asia & 11 & 1013 & 1155 & 2.76 & $(2.29-3.33)$ & 10.58 & $<0.001$ & $46.50 \%$ \\
\hline & non-Asia & 3 & 159 & 44 & 0.90 & $(0.48-1.71)$ & 0.32 & $>0.05$ & $0.00 \%$ \\
\hline \multirow{3}{*}{ Differentiation degree } & overall & 10 & 389 & 1411 & 1.83 & $(1.45-2.31)$ & 5.06 & $<0.001$ & $37.80 \%$ \\
\hline & Asia & 9 & 375 & 1385 & 1.87 & $(1.47-2.37)$ & 5.16 & $<0.001$ & $40.80 \%$ \\
\hline & non-Asia & 1 & 14 & 26 & 0.90 & $(0.22-3.75)$ & 0.14 & $>0.05$ & - \\
\hline \multirow{3}{*}{ OS } & overall & 7 & 860 & 291 & 2.15 & $(1.64-2.65)$ & 8.33 & $<0.001$ & $0.00 \%$ \\
\hline & Asia & 5 & 693 & - & 2.17 & $(1.60-2.74)$ & 7.44 & $<0.001$ & $0.00 \%$ \\
\hline & non-Asia & 2 & 167 & - & 2.07 & $(0.98-3.15)$ & 3.74 & $<0.001$ & $0.00 \%$ \\
\hline
\end{tabular}

OS, overall survival; OR, odds ratio; HR, hazard ratio.

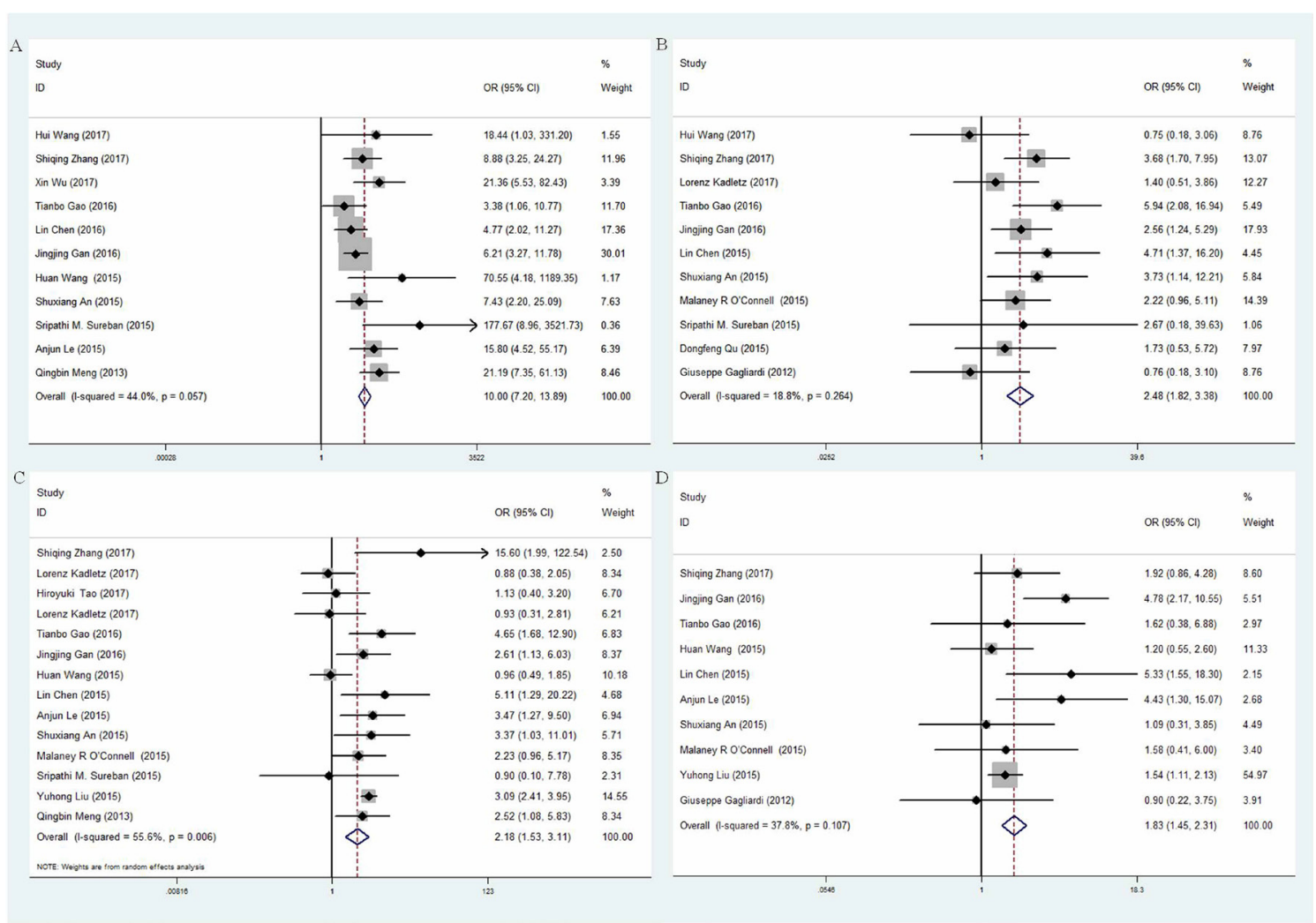

Figure 2: Forest plot of odd ratio (OR) of subgroup analysis. (A) subgroup analysis based on control tissues; (B) subgroup analysis based on TNM stage; (C) subgroup analysis based on lymphatic metastasis; (D) subgroup analysis based on differentiation. 
Table 4: Summarized results of diagnostic criteria

\begin{tabular}{|c|c|c|c|c|c|c|c|c|c|c|}
\hline Subgroup & Category & $\begin{array}{c}\text { Study } \\
\text { number }\end{array}$ & Patients(n) & Controls(n) & Sensitivity & Specificity & PLR & NLR & DOR & AUC \\
\hline All combined & Overall & 11 & 674 & 488 & $0.58(0.51-0.66)$ & $0.90(0.82-0.95)$ & $5.9(3.3-10.5)$ & $0.46(0.39-0.55)$ & $13(7-24)$ & 0.78 \\
\hline \multirow{2}{*}{ Sample size } & $\geq 50$ & 8 & 572 & 389 & $0.62(0.44-0.77)$ & $0.85(0.67-0.94)$ & $4.1(2.1-7.9)$ & $0.45(0.32-0.62)$ & $9(5-116)$ & 0.79 \\
\hline & $>50$ & 3 & 102 & 99 & $0.76(0.67-0.84)$ & $0.78(0.68-0.86)$ & $4.78(1.21-18.88)$ & $0.30(0.20-0.47)$ & $17(3-93)$ & 0.81 \\
\hline \multirow{2}{*}{ Blinded } & Yes & 6 & 475 & 361 & $0.55(0.44-0.67)$ & $0.95(0.87-0.98)$ & $10.9(3.9-30.2)$ & $0.47(0.36-0.62)$ & $23(7-76)$ & 0.85 \\
\hline & No & 5 & 199 & 127 & $0.78(0.52-0.92)$ & $0.67(0.40-0.86)$ & $2.4(1.4-4.1)$ & $0.33(0.18-0.62)$ & $7(4-14)$ & 0.79 \\
\hline \multirow{2}{*}{ Method } & Multiplication & 5 & 335 & 261 & $0.58(0.44-0.72)$ & $0.90(0.73-0.97)$ & $6.0(2.1-16.8)$ & $0.46(0.34-0.63)$ & $13(4-39)$ & 0.77 \\
\hline & Addition & 6 & 339 & 227 & $0.75(0.44-0.92)$ & $0.78(0.54-0.92)$ & $3.5(1.9-6.4)$ & $0.32(0.14-0.72)$ & $11(6-22)$ & 0.84 \\
\hline \multirow{2}{*}{ Region } & Asia & 9 & 614 & 424 & $0.58(0.49-0.65)$ & $0.88(0.79-0.93)$ & $4.6(2.9-7.5)$ & $0.48(0.42-0.56)$ & $10(6-16)$ & 0.76 \\
\hline & non-Asia & 2 & 60 & 64 & $0.93(0.84-0.98)$ & $0.44(0.31-0.57)$ & $6.06(0.00-7848)$ & $0.18(0.08-0.39)$ & $54(5-530)$ & - \\
\hline
\end{tabular}

differentiated cancers, positive lymph node metastasis and advanced clinical stage, suggesting that overexpression of DCLK1 markedly accelerated the pathogenesis and development of cancer. Furthermore, we also found that patients with high DCLK1 expression had significantly poor overall survival, indicating that DCLK1 may be a promising biomarker that helps to identify patients with a high risk for recurrence in cancer. In subgroup analysis stratified by geographic region (Asia vs non-Asia), overexpression of DCLK1 was significantly correlated with advanced clinical stage and poor overall survival for all people, and non-significant heterogeneity was found
$\left(\mathrm{I}^{2}=0.00 \%\right)$. However, high DCLK1 expression was only notably correlated with positive lymph node metastasis and poorly differentiated cancer in Asian region but not in non-Asia region.

Additionally, we assessed the diagnostic accuracy of DCLK1 in malignant tumors. The overall pooled sensitivity and specificity were $0.58(95 \% \mathrm{CI}=$ $0.51-0.66)$ and $0.90(95 \% \mathrm{CI}=0.82-0.95)$, respectively, which suggested that DCLK1 had a relatively considerable accuracy in detecting malignant tumors. The PLR of 5.9 $(95 \% \mathrm{CI}=3.3-10.5)$ suggested that patients with cancer have a 5.9 -fold higher chance of being DCLK1 test

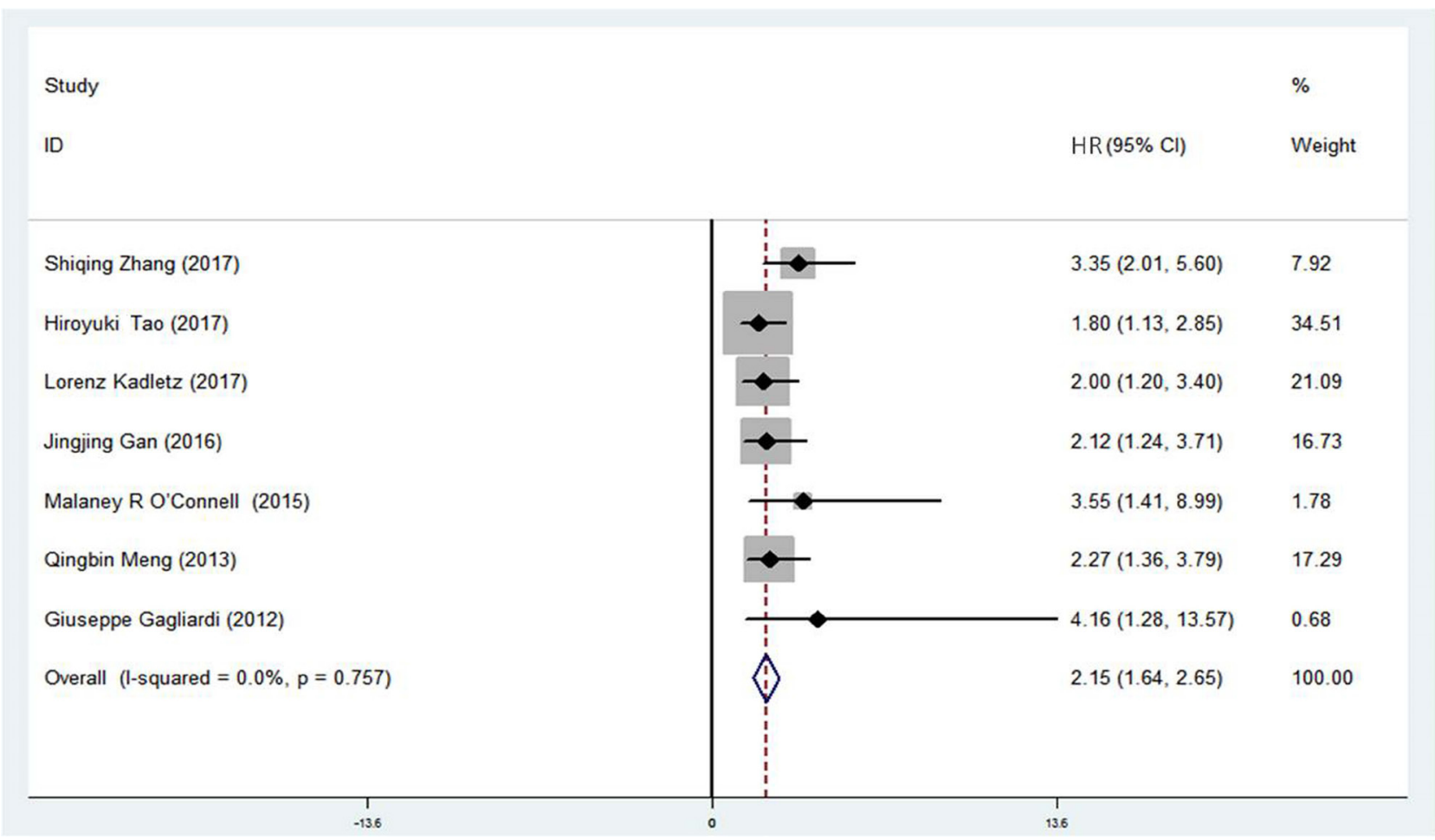

Figure 3: Association between DCLK1 and overall survival for patients with cancer. 
positive compared to individuals without cancer. Similarly, the NLR of $0.46(95 \% \mathrm{CI}=0.39-0.55)$ indicated that low expression of DCLK1 might help exclude non-cancer individuals. These ratios suggested a potential role of DCLK1 for clinical confirmation and exclusion purpose. The DOR is the ratio of the odds of positivity in patients relative to the odds of positivity in control subjects, with higher values indicating better discriminatory test performance. In our meta-analysis, the value of DOR was 13, indicating that DCLK1 could be used as a biomarker for the diagnosis of malignant tumors. When sensitivity and specificity were considered simultaneously, the AUC of DCLK1 was 0.78 , suggesting that the test performance of DCLK1 in discerning cancer tissues is reasonably good.

Studies have shown that DCLK1 negatively regulates tumor suppressor miRNAs and promotes epithelial-mesenchymal transition (EMT), a process through which polarized epithelial cells undergo multiple biochemical changes, leading to a mesenchymal phenotype, such as enhanced migratory capacity, invasiveness, and resistance to apoptosis $[9,18,26]$. Furthermore, DCLK1 has been shown to decrease tumor suppressor miRNAs let-7a, miR-200, miR-144, and miR$143 / 145$ and subsequently up-regulate their downstream targets, including c-MYC, EMT-associated transcription factors ZEB1, ZEB2, Snail and Slug in HCC, CRC and PDAC, thereby promoting the development of cancer $[9,18,27]$. In addition, DCLK1 also regulates Notch-1 via a miR-144 dependent mechanism and its downstream effector HES1 to promote tumor xenograft growth [28]. Knockdown of DCLK1 or application of small molecule kinase inhibitors for DCLK1 could result in a delay of tumor development by down-regulating miRNAs downstream pluripotency transcription factors, EMT and critical oncogenic pathways $[18,26,27,29]$. Recently, it has been reported that combination of DCLK1 inhibition with irradiation has a synergistic effect in HNSCC cell lines [11]. DCLK1 is therefore considered as an
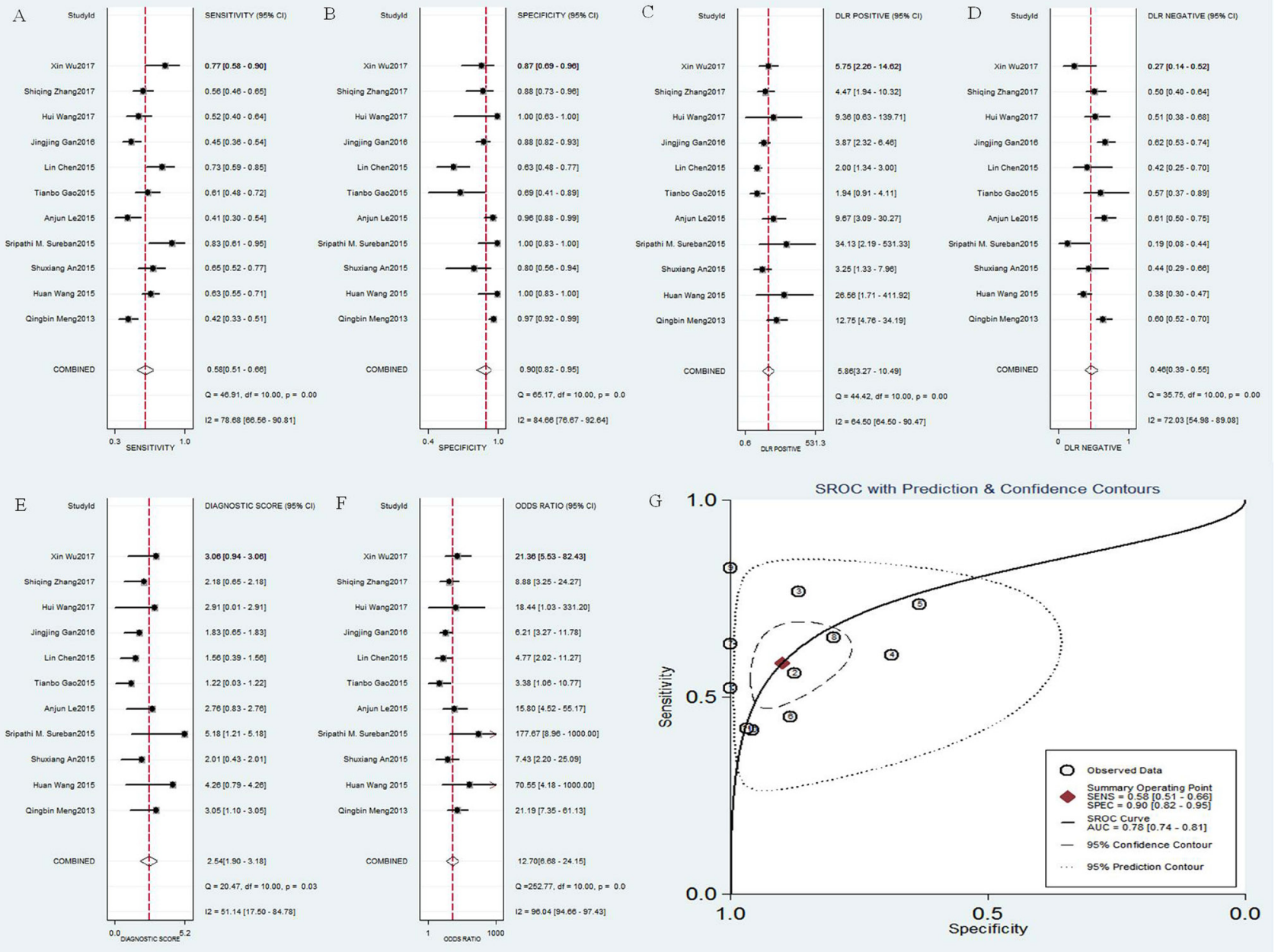

Figure 4: Diagnostic accuracy of DCLK1 in cancer. (A) sensitivity of DCLK1 for the diagnosis of cancer; (B) specificity of DCLK1 for the diagnosis of cancer; (C) positive likelihood ratio (PLR) of DCLK1 for the diagnosis of cancer; (D) negative likelihood ratio (NLR) of DCLK1 for the diagnosis of cancer; (E) diagnostic score of DCLK1 for the diagnosis of cancer; (F) diagnostic odds ratio (DOR) of DCLK1 for the diagnosis of cancer; (G) the corresponding area under the SROC curve (AUC) of DCLK1 for the diagnosis of cancer. 
attractive and potential therapeutic target in the treatment of malignant tumors $[30,31]$. Due to the limitations of currently available evidence on the therapeutic effects and molecular biology of DCLK1 in malignant tumors, Further studies are warranted to investigate these in more detail.

There was significant heterogeneity exiting across the included studies, which is a potential obstacle. Firstly, the heterogeneity was probably due to differences in cancer types included in this meta-analysis. Secondly, variable cut-off points were used in different studies, which may lead to the threshold effect contributing to heterogeneity, even calculated Spearman correlation coefficient value was $-0.58(p=0.34)$. In addition, we found DCLK1 has higher diagnostic accuracy for malignant tumors in small samples using univariate metaregression analysis and subgroup analysis, suggesting that sample size may be partially the cause of heterogeneity in sensitivity and specificity.

Though it was the first meta-analysis to assess the diagnostic and prognostic role of DCLK1 in cancer, there were still several limitations in our study. First, the majority of the studies in this meta-analysis were retrospective investigations conducted in Asia, which may result in potential selection bias. Second, despite a systematic and exhaustive literature search was performed, the sample sizes and number of included studies were relatively small, which may place restrictions on evaluating the diagnostic performance of DCLK1.

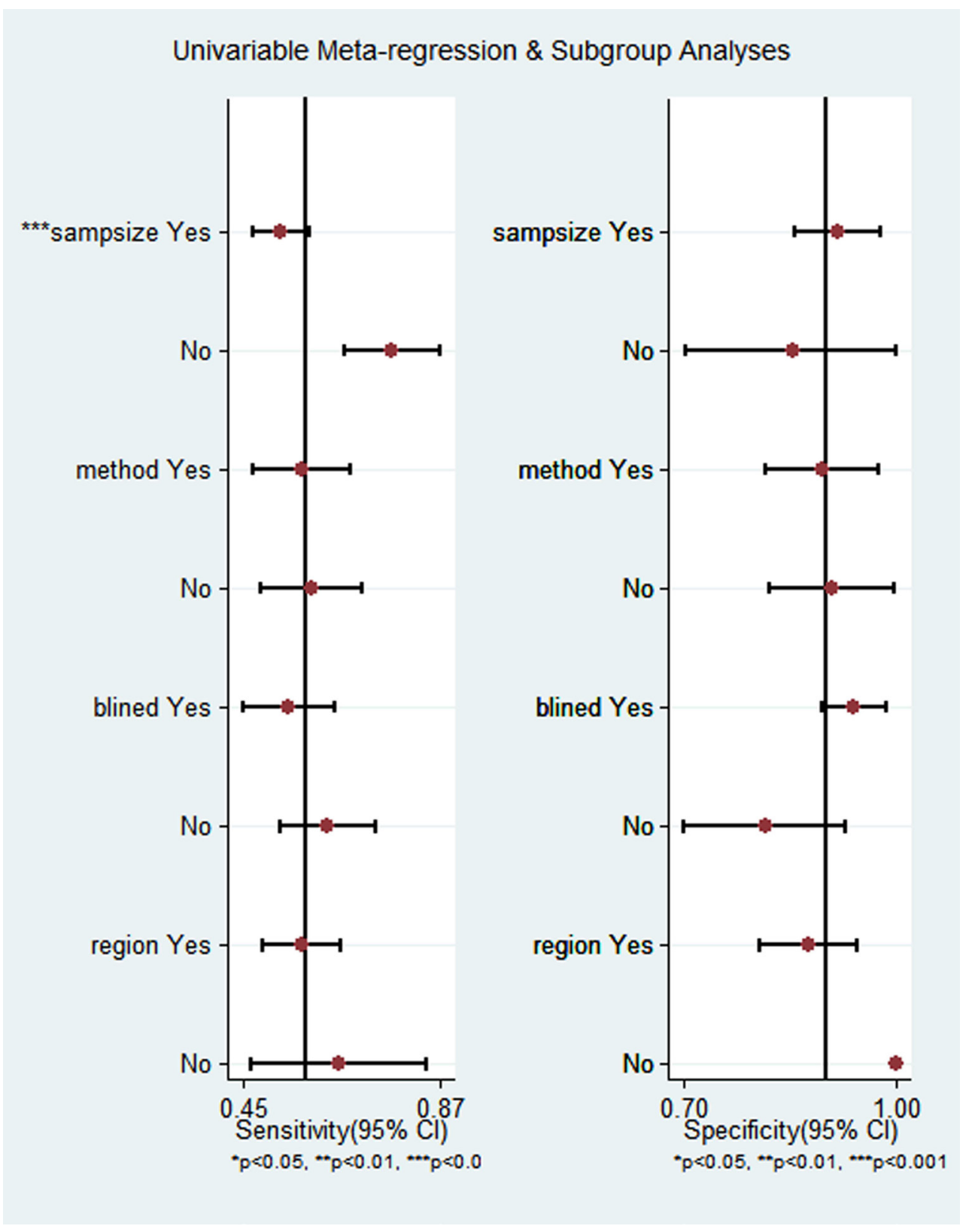

Figure 5: Univariable meta-regression and subgroup analysis. 
Third, we could not determine the optimal cut-off value for DCLK1 due to use of different cut-off values for the examined sample set.

Despite these limitations, the meta-analysis still provided credible evidence that up-regulation of DCLK1 was an early event in the carcinogenesis and progression of malignant tumors. Expression level of DCLK1 was closely correlated to tumor differentiation, lymph node invasion and clinical phase of the patients. It was useful for predicting development of malignant tumors and clinical outcome of cancer patients. In addition, DCLK1 was potential to be a promising diagnostic and prognostic biomarker for malignant tumors, and might serve as an attractive therapeutic target in the treatment of malignant tumors.

\section{MATERIALS AND METHODS}

\section{Search strategy}

Two independent reviewers performed a comprehensive and systematic literature search to identify relevant studies from the databases of PubMed, Medline, Embase, Chinese National Knowledge Infrastructure (CNKI) and Wanfang databases (from inception through July 2017). The search strategy used following free
A

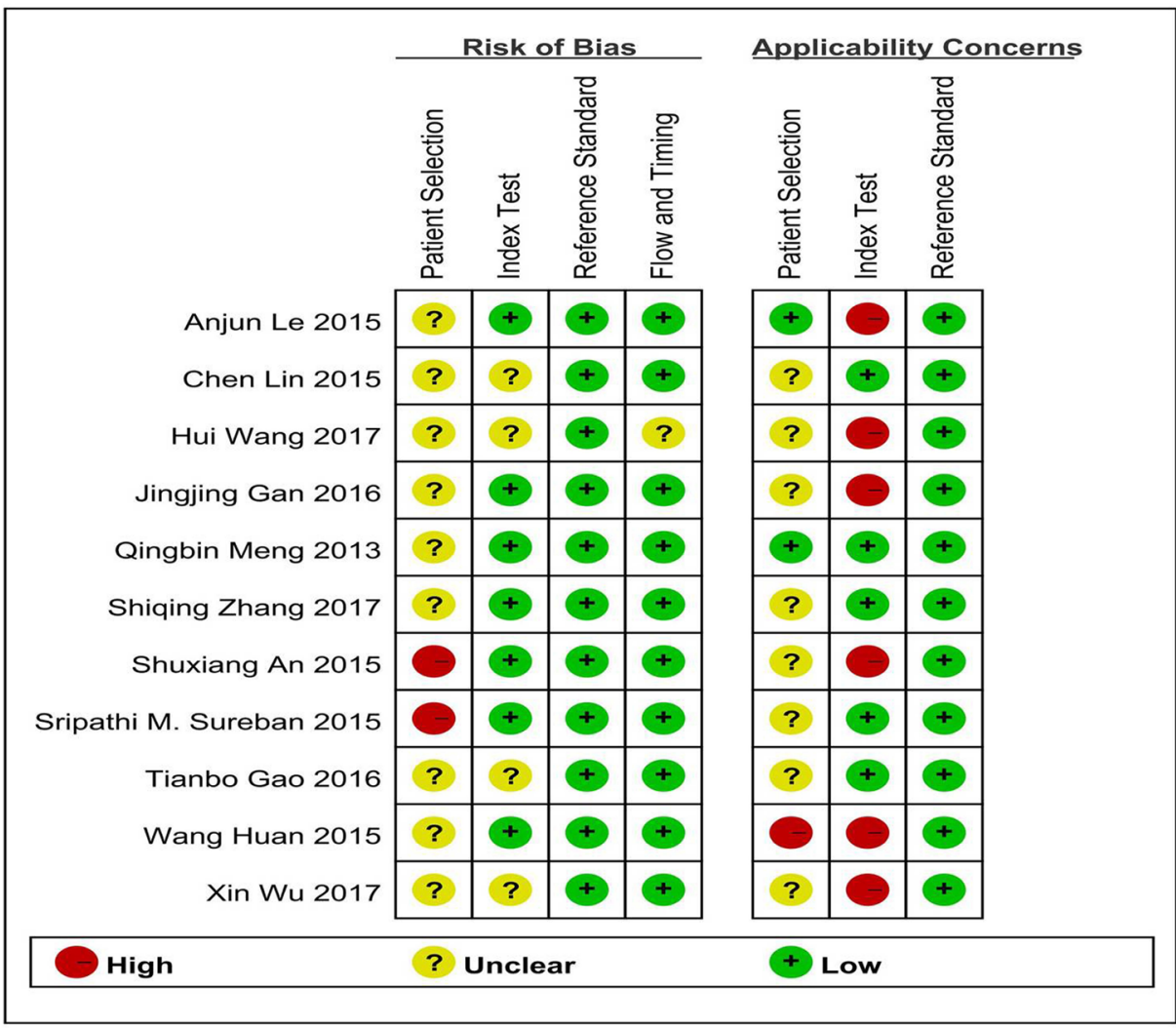

B

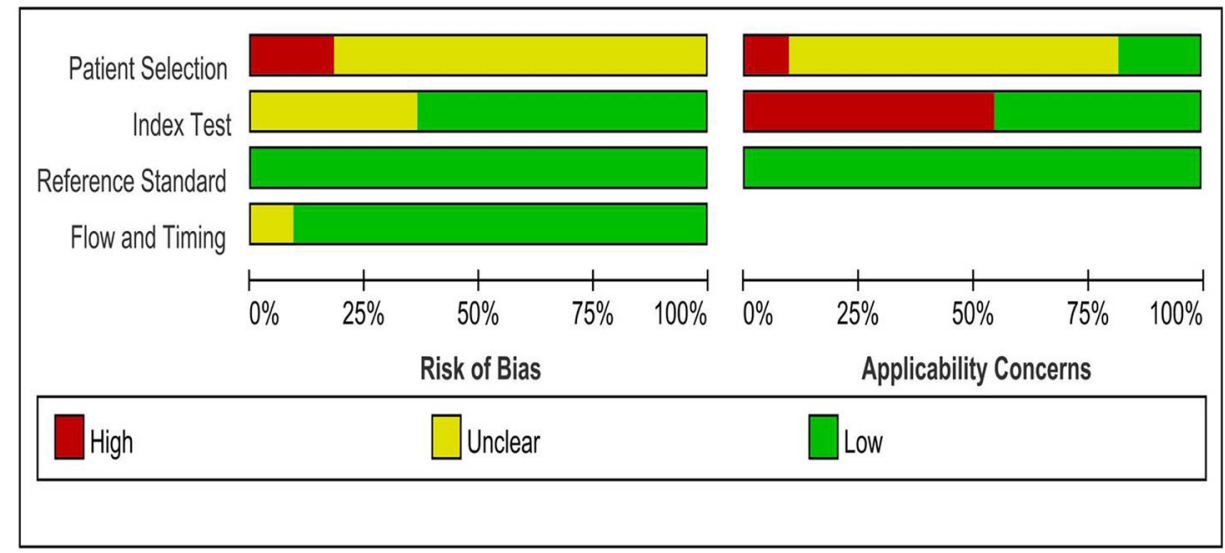

Figure 6: Assessment of methodological quality of diagnostic accuracy studies. (A) risk of bias and applicability concerns summary; (B) risk of bias and applicability concerns graph. 
text and Medical Subject Heading terms to increase sensitivity. The search strings was: ("cancer" or "tumor" or "carcinoma" or "tumors" or "neoplasm" or "malignant neoplasm" or "malignant tumors") and ("Doublecortin and CaM kinase-like-1" or "Doublecortin-like kinase 1" or "DCLK1" or "KIAA0369"). All searches were restricted to English and Chinese publications. The reference lists of relevant articles were manually searched.

\section{Inclusion and exclusion criteria}

The inclusion criteria: (1) sufficient data on DCLK1 expression in malignant tumors; (2) case-control, crosssectional, or cohort studies; (3) inclusion of pathologically confirmed patients; (4) patient tissues were taken prior to chemotherapy, radiotherapy and other drug treatment. The exclusion criteria: (1) reviews, editorials, expert opinions and case reports; (2) no useful data reported; (3) non-human studies; (4) unqualified or did not provide sufficient data.

\section{Data extraction and quality assessment of studies}

We carried out this meta-analysis in accordance with PRISMA guidelines [32]. The following types of characteristics were extracted: study characteristics (the name of first author, publication year, country, enrolled period, study design and testing method of DCLK1), patient characteristics (age, sex, numbers of patients, case number of different groups, histological classification, tumor differentiation degree, tumor node metastases, TNM classification, $\mathrm{HR}$ and 95\% CI), and concrete data of DCLK1 expression (number of true positives, false negatives, false positives, and true negatives). We systematically assessed the quality of primary studies using the Newcastle-Ottawa Scale (NOS) [33], and assessed the methodological quality based on the QUADAS-2 list to ensure that the enrolled studies were accurate and reliable [34]. Any disagreements were discussed and resolved by consensus.

\section{Statistical analysis}

After sufficient data were collected and identified, we calculated the pooled OR and 95\% CI using two different meta-analysis approaches according to heterogeneity. The chi-squared test and $I^{2}$ test were used to evaluate the heterogeneity of the studies and considered significant at $p<0.1$ or $\mathrm{I}^{2}>50 \%$ [35]. We calculated the effect sizes using fixed effects models with low heterogeneity $\left(\mathrm{I}^{2}<\right.$ $50 \%$ or $p>0.1)$. Otherwise, a random-effects model was presented [36]. If necessary, we performed meta-regression and subgroup analysis to explore potential sources of heterogeneity. Pooled sensitivity, specificity, PLR, NLR, DOR and their 95\%CI were displayed as forest plots [37]. In addition, we extracted the $\mathrm{HR}$ and $95 \% \mathrm{CI}$ from the papers to perform meta-analysis of HR to determine the association of DCLK1 expression with survival of patients.
Funnel plots, Egger's test and Deeks' funnel plot were implemented to measure potential publication bias, $p \geq$ 0.05 indicates no publication bias [38, 39], and sensitivity analysis was performed to evaluate whether exclusion of any individual study affects the overall results. All statistical analyses were performed using STATA software (Version 12.0; STATA Corporation, College Station, TX). Two-tailed $p$ values $<0.05$ were considered statistically significant (except for the heterogeneity and publication bias tests already mentioned).

\section{Abbreviations}

CRC, colorectal cancer; GC, gastric cancer; BCA, breast carcinoma; NSCLC, non-small cell lung cancer; HCC, hepatocellular carcinoma; SGC, salivary gland carcinoma; HNSCC, head and neck squamous cell carcinoma; OSCC, oral squamous-cell carcinoma; PDAC, pancreatic ductal adenocarcinoma; MPM, malignant pleural mesothelioma; BC, bladder cancer; IHC, immunohistochemistry; RT-PCR, real time polymerase chain reaction; TP, true positive; FP, false positive; FN, false negative; TN, true negative; OS, overall survival; HR, hazard ratio; U, univariate analysis; DCLK1, Doublecortinlike kinase 1; OR, odds ratio; PLR, positive likelihood ratio; NLR, negative likelihood ratio; DOR, diagnostic odds ratio; SROC, summary receiver operating characteristic.

\section{Author contributions}

Wenhua Shi and Manxiang Li designed the study. Fangwei $\mathrm{Li}$ and Shaojun $\mathrm{Li}$ performed the literature research, literature selection and data extraction. Qingting Wang and Xin Yan assessed the quality of studies. Wenhua Shi, Fangwei Li and Jian Wang analyzed the data. Wenhua Shi, Qianqian Zhang, Limin Chai wrote the first draft of the manuscript. All authors contributed to the writing of the manuscript results and conclusions.

\section{CONFLICTS OF INTEREST}

None of the authors has any conflicts of interest to declare.

\section{FUNDING}

This study was supported by the National Natural Science Foundation of China (Grant No. 81330002).

\section{REFERENCES}

1. Siegel RL, Miller KD, Jemal A. Cancer Statistics, 2017. CA Cancer J Clin. 2017; 67:7-30. https://doi.org/10.3322/ caac. 21387.

2. Huang HY, Shi JF, Guo LW, Bai YN, Liao XZ, Liu GX, Mao AY, Ren JS, Sun XJ, Zhu XY, Wang L, Song BB, Du LB, 
et al. Expenditure and financial burden for the diagnosis and treatment of colorectal cancer in China: a hospital-based, multicenter, cross-sectional survey. Chin J Cancer. 2017; 36: 41. https://doi.org/10.1186/s40880-017-0209-4.

3. Martinez-Perez C, Turnbull AK, Ekatah GE, Arthur LM, Sims AH, Thomas JS, Dixon JM. Current treatment trends and the need for better predictive tools in the management of ductal carcinoma in situ of the breast. Cancer Treat Rev. 2017; 55:163-72. https://doi.org/10.1016/j.ctrv.2017.03.009.

4. Honore PM, Jacobs R, Hendrickx I, De Waele E, Van Gorp V, Joannes-Boyau O, De Regt J, Boer W, Spapen HD. Biomarkers in critical illness: have we made progress? Int J Nephrol Renovasc Dis. 2016; 9:253-6. https:/doi. org/10.2147/ijnrd.s113219.

5. Chan DL, Clarke SJ, Diakos CI, Roach PJ, Bailey DL, Singh S, Pavlakis N. Prognostic and predictive biomarkers in neuroendocrine tumours. Crit Rev Oncol Hematol. 2017; 113:268-82. https://doi.org/10.1016/j. critrevonc.2017.03.017.

6. Lin PT, Gleeson JG, Corbo JC, Flanagan L, Walsh CA. DCAMKL1 encodes a protein kinase with homology to doublecortin that regulates microtubule polymerization. J Neurosci. 2000; 20:9152-61.

7. Weygant N, Qu D, May R, Tierney RM, Berry WL, Zhao L, Agarwal S, Chandrakesan P, Chinthalapally HR, Murphy NT, Li JD, Sureban SM, Schlosser MJ, et al. DCLK1 is a broadly dysregulated target against epithelial-mesenchymal transition, focal adhesion, and stemness in clear cell renal carcinoma. Oncotarget. 2015; 6:2193-205. https://doi. org/10.18632/oncotarget.3059.

8. Qu D, Johnson J, Chandrakesan P, Weygant N, May R, Aiello N, Rhim A, Zhao L, Zheng W, Lightfoot S, Pant S, Irvan J, Postier R, et al. Doublecortin-like kinase 1 is elevated serologically in pancreatic ductal adenocarcinoma and widely expressed on circulating tumor cells. PLoS One. 2015; 10:e0118933. https://doi.org/10.1371/journal. pone. 0118933 .

9. Gao T, Wang M, Xu L, Wen T, Liu J, An G. DCLK1 is up-regulated and associated with metastasis and prognosis in colorectal cancer. J Cancer Res Clin Oncol. 2016; 142: 2131-40. https://doi.org/10.1007/s00432-016-2218-0.

10. Liu YH, Tsang JY, Ni YB, Hlaing T, Chan SK, Chan KF, Ko CW, Mujtaba SS, Tse GM. Doublecortin-like kinase 1 expression associates with breast cancer with neuroendocrine differentiation. Oncotarget. 2016; 7:146476. https://doi.org/10.18632/oncotarget.6386.

11. Kadletz L, Thurnher D, Wiebringhaus R, Erovic BM, Kotowski U, Schneider S, Schmid R, Kenner L, Heiduschka G. Role of cancer stem-cell marker doublecortin-like kinase 1 in head and neck squamous cell carcinoma. Oral Oncol. 2017; 67:109-18. https://doi. org/10.1016/j.oraloncology.2017.02.007.

12. Tao H, Tanaka T, Okabe K. Doublecortin and CaM kinaselike-1 expression in pathological stage I non-small cell lung cancer. J Cancer Res Clin Oncol. 2017. https://doi. org/10.1007/s00432-017-2405-7.

13. Wu X, Ruan Y, Jiang H, Xu C. MicroRNA-424 inhibits cell migration, invasion, and epithelial mesenchymal transition by downregulating doublecortin-like kinase 1 in ovarian clear cell carcinoma. Int J Biochem Cell Biol. 2017; 85: 66-74. https://doi.org/10.1016/j.biocel.2017.01.020.

14. Chen L. The expression and meaning of MIR-217 and DCLK1 in gastric cancer.University of south china. 2015.

15. Gan J. Expression of DCLK1 in breast cancer and its prognostic significance. Nan hua university. 2016.

16. Wang H, Ma F, Liu B, Shi M, Xiao W. DCLK1+/Ki67- cell morphology and distribution in colorectal cancer. Chinese Journal of Tissue Engineering Research. 2015; 19:1575-9. https://doi.org/10.3969/j.issn.2095-4344.2015.10.018.

17. An S, Sun B, Zhao D, Lei L, Liu J. Expression and Signifi cance of Doublecortin-Like Kinase 1 in colorectal neoplasia. Chin J Hemorh. 2015; 25:135-8. https://doi. org/10.3969/j.issn.1009-881X.2015.02.005.

18. Sureban SM, Madhoun MF, May R, Qu D, Ali N, Fazili J, Weygant N, Chandrakesan P, Ding K, Lightfoot SA, Houchen CW. Plasma DCLK1 is a marker of hepatocellular carcinoma (HCC): Targeting DCLK1 prevents HCC tumor xenograft growth via a microRNA-dependent mechanism. Oncotarget. 2015; 6:37200-15. https://doi.org/10.18632/oncotarget.5808.

19. Le A. The expression of DCLK1 in colorecbl cancer, colorectal adenomas and the clinical research. Yangzhou university. 2016.

20. Meng QB, Yu JC, Kang WM, Ma ZQ, Zhou WX, Li J, Zhou L, Cao ZJ, Tian SB. Expression of doublecortin-like kinase 1 in human gastric cancer and its correlation with prognosis. [Article in Chinese]. Zhongguo Yi Xue Ke Xue Yuan Xue Bao. 2013; 35:639-44. https://doi.org/10.3881/j.issn.1000503X.2013.06.010.

21. Kadletz L, Aumayr K, Heiduschka G, Schneider S, Enzenhofer E, Lill C. Overexpression of DCLK1 is predictive for recurrent disease in major salivary gland malignancies. Eur Arch Otorhinolaryngol. 2017; 274: 467-75. https://doi.org/10.1007/s00405-016-4227-7.

22. O’Connell MR, Sarkar S, Luthra GK, Okugawa Y, Toiyama Y, Gajjar AH, Qiu S, Goel A, Singh P. Epigenetic changes and alternate promoter usage by human colon cancers for expressing DCLK1-isoforms: Clinical Implications. Sci Rep. 2015; 5:14983. https://doi.org/10.1038/srep14983.

23. Gagliardi G, Goswami M, Passera R, Bellows CF. DCLK1 immunoreactivity in colorectal neoplasia. Clin Exp Gastroenterol. 2012; 5:35-42. https://doi.org/10.2147/CEG. S30281.

24. Wang H, Dai YY, Zhang WQ, Hsu PC, Yang YL, Wang YC, Chan G, Au A, Xu ZD, Jiang SJ, Wang W, Jablons DM, You L. DCLK1 is correlated with MET and ERK5 expression, and associated with prognosis in malignant pleural mesothelioma. Int J Oncol. 2017; 51:91-103. https://doi. org/10.3892/ijo.2017.4021. 
25. Zhang S, Zhang G, Guo H. DCAMKL1 is associated with the malignant status and poor outcome in bladder cancer. Tumour Biol. 2017; 39:1010428317703822. https://doi. org/10.1177/1010428317703822.

26. Sureban SM, May R, Qu D, Weygant N, Chandrakesan P, Ali N, Lightfoot SA, Pantazis P, Rao CV, Postier RG, Houchen CW. DCLK1 regulates pluripotency and angiogenic factors via microRNA-dependent mechanisms in pancreatic cancer. PLoS One. 2013; 8:e73940. https://doi. org/10.1371/journal.pone.0073940.

27. Verissimo CS, Elands R, Cheng S, Saaltink DJ, ter Horst JP, Alme MN, Pont C, van de Water B, Havik B, Fitzsimons CP, Vreugdenhil E. Silencing of doublecortin-like (DCL) results in decreased mitochondrial activity and delayed neuroblastoma tumor growth. PLoS One. 2013; 8:e75752. https://doi.org/10.1371/journal.pone.0075752.

28. Sureban SM, May R, Mondalek FG, Qu D, Ponnurangam S, Pantazis P, Anant S, Ramanujam RP, Houchen CW. Nanoparticle-based delivery of siDCAMKL-1 increases microRNA-144 and inhibits colorectal cancer tumor growth via a Notch-1 dependent mechanism. J Nanobiotechnology. 2011; 9:40. https://doi.org/10.1186/1477-3155-9-40.

29. Sureban SM, May R, Weygant N, Qu D, Chandrakesan P, Bannerman-Menson E, Ali N, Pantazis P, Westphalen CB, Wang TC, Houchen CW. XMD8-92 inhibits pancreatic tumor xenograft growth via a DCLK1-dependent mechanism. Cancer Lett. 2014; 351:151-61. https://doi. org/10.1016/j.canlet.2014.05.011.

30. Sun AJ, Gao HB, Liu G, Ge HF, Ke ZP, Li S. Identification of MSX1 and DCLK1 as mRNA Biomarkers for Colorectal Cancer Detection Through DNA Methylation Information. J Cell Physiol. 2017; 232:1879-84. https://doi.org/10.1002/ jcp. 25733.

31. Qiao S, Zhao Y, Geng S, Li Y, Hou X, Liu Y, Lin FH, Yao L, Tian W. A novel double-targeted nondrug delivery system for targeting cancer stem cells. Int J Nanomedicine. 2016; 11:6667-78. https://doi.org/10.2147/ijn.s116230.

32. Moher D, Liberati A, Tetzlaff J, Altman DG. Preferred reporting items for systematic reviews and meta-analyses: the PRISMA statement. Int J Surg. 2010; 8:336-41. https:// doi.org/10.1016/j.ijsu.2010.02.007.

33. Nnoaham KE, Clarke A. Low serum vitamin D levels and tuberculosis: a systematic review and meta-analysis. Int J Epidemiol. 2008; 37:113-9. https://doi.org/10.1093/ije/ dym247.

34. Whiting PF, Rutjes AW, Westwood ME, Mallett S, Deeks JJ, Reitsma JB, Leeflang MM, Sterne JA, Bossuyt PM. QUADAS-2: a revised tool for the quality assessment of diagnostic accuracy studies. Ann Intern Med. 2011; 155:529-36. https://doi.org/10.7326/0003-4819-155-8201110180-00009.

35. Higgins JP, Thompson SG, Deeks JJ, Altman DG. Measuring inconsistency in meta-analyses. BMJ. 2003; 327:557-60. https://doi.org/10.1136/bmj.327.7414.557.

36. DerSimonian R, Laird N. Meta-analysis in clinical trials revisited. Contemp Clin Trials. 2015; 45:139-45. https:// doi.org/10.1016/j.cct.2015.09.002.

37. Moses LE, Shapiro D, Littenberg B. Combining independent studies of a diagnostic test into a summary ROC curve: data-analytic approaches and some additional considerations. Stat Med. 1993; 12:1293-316.

38. Egger M, Davey Smith G, Schneider M, Minder C. Bias in meta-analysis detected by a simple, graphical test. BMJ. 1997; 315:629-34.

39. Deeks JJ, Macaskill P, Irwig L. The performance of tests of publication bias and other sample size effects in systematic reviews of diagnostic test accuracy was assessed. J Clin Epidemiol. 2005; 58:882-93. https://doi.org/10.1016/j. jclinepi.2005.01.016. 